Ciência e Natura, Santa Maria, v. 37 n. 3 esp. 2015, p. 09-15

Revista do Centro de Ciências Naturais e Exatas - UFSM

ISSN impressa: 0100-8307 ISSN on-line: 2179-460X

\title{
ciênciaenatura
}

\section{Designing predictive controller based on nonlinear model for multi- stage MED desalination systems}

\author{
Ali Soleymanizadeh", ${ }^{1,}$, Heidar Ali Shayanfar ${ }^{2}$ \\ ${ }^{1}$ Department of Engineering, South Tehran Branch, Islamic Azad University, Tehran, Iran
}

\begin{abstract}
Due to the use of fossil energy and environmentally pollutant fuels, groundwater and surface water pollution has led to a more progressive movement towards the technology of desalination systems in recent decades so that the issue of the desalination of seawaters and ocean waters has received great attention from most countries. In the meantime, the use of distillation desalination systems has been welcomed more than other systems because they take advantage of the sun's energy and do not negatively influence the environment. The $P D E$ and nonlinear model of multi-effect desalination systems constitutes the structure under study in this paper. In order to control the variables of this model, a nonlinear predictive model controller (NPMC) has been proposed. The results obtained from the conduct of this controller on multi-effect desalination system in MATLAB Software is indicative of the acceptable performance of the controller.
\end{abstract}

Keyword: Desalination systems, multi-stage distillation, predictive control, nonlinear predictor 


\section{INTRODUCTION}

$\mathrm{D}$ ue to the huge increase in world population, the demand for water has increased dramatically so that the supply of drinking water has become one of the main problems of all the countries today. On the one hand, available water resources are declining; on the other hand, well drilling in some areas will not make any contribution to this problem due to lack of access to fresh shallow groundwater and the drought arising from lack of rain. Therefore, other methods such as water sweetening or desalination, which have been of interest from the old time, should have been taken into consideration whereas they have been used only in special cases due to the high cost and low efficiency of these methods. Today, the employment of desalination technology is sometimes even less expensive than dam construction, dredging, maintenance, and transfer of dam waters as per the estimates made in this regard. With the advancement of this technology, the production of fresh water for drinking, industrial, agricultural, and other usages will be an affordable and costeffective action in the future [1].

Water as a basic material is necessary to the life of every creature. Research has shown that 94 percent of the available water on the Earth is salty, 3 percent of freshwater lies in the North and South poles in the form of ice, and only about 3 percent of water on the planet earth is healthy and potable. About less than one percent of this amount of fresh water is available to humans whose 3.2 percent is used in agriculture. Thus, the desalination of seawaters and ocean waters is greatly considered by most countries [2].

In cases where the fresh water does not exist in the region or is not enough, the water in that area is so salty that it is not usable, and carrying or transferring fresh water to that area from other areas is not economical, the only way to provide water seems to be saltwater sweetening or desalination. The process of desalination from huge bulks of seawater reserves and saltwater has become an important and new source of fresh water production.

Desalination usually refers to a process in which the concentration of solid minerals in the water or the water salinity is reduced. Clearly, seawater is very salty and there is not the possibility of direct use of it in industrial and domestic usages (such as boilers, steam turbines, and distillation and wash towers). Water desalination prepares it to be used for this purpose. Common methods of water sweetening which are mostly used for high capacity instances include multi-stage flash distillation (MSF), multi-effect distillation (ME), vapor compression (VC) and reverse osmosis (RO) [3].

In reference [4], all thermal desalination systems have been analyzed and compared in terms of performance and heat transfer levels by proposing an algorithm for the simulation of the process in steady state. After the comparison of the MSD systems without vapor compression systems, thermal compression MED-TVC systems, and mechanical compression systems of MEDMVC, MVC assessment systems together, the performance of TVC systems was assessed to be higher than that of MVC systems. The results obtained from this reference predict the decrease of the proportion of performance for increasing the temperature of input steam.

In reference [5], the equations pertaining to the multi-stage evaporation system are presented and, then, its performance has been assessed based on a function of changes in important input parameters. In this reference, MED system and its functional characteristics have been evaluated superior to MSF system with estimating the surface of special heat transfer, the flow rate of cooling water, and the comparison of the results of that study with those of the previous ones. 
In reference [6], the steady conditions of one MED desalination system have been analyzed. This reference has examined the effect of the steam entering the system and the temperature of the first stage on performance proportion. In this reference, it has been stated that performance proportion increases with the rise in the temperature of the first stage, no reason has been mentioned for it and for the possible negative effects of the temperature increase on the system.

In reference [7], the need to analyze and improve the performance of MED units has been reiterated due to the progress of MED units in the world. In this regard, the equations pertaining to MED units have been formed in such a way that the inequality between the temperatures of feeding water of each step can be investigated. In the following, the obtained results have been compared with the MED units in operation. In addition, the proportion of optimal performance has been obtained within the range of 8.5 to 18.5 and the maximum temperature between 55.8 and 67.5 for 4 -to12-stage units.

In this study, a PDE and nonlinear model for multi-effect desalination systems has been selected from among the new resources presented in this research. In the following, a nonlinear predictive model-based controller (NPMC) has been proposed to control the variables available in MED structure. This controller has two advantages: first, it does not suffer such problems existing in the conventional MPC structure as the inability to cope with the delays in the system, and, second, the nonlinearity of the model has made this controller more efficient. In addition, the practicality and simplicity of the proposed method cannot be ignored.

The present study has been organized in five sections. In the second section, a PDE and nonlinear model has been proposed out of MED systems. The structure of the proposed controller and the relevant mathematical relations belong to the third section. The results obtained from the implementation of NMPC controller on MED systems have been included in the fourth section. Last but not least, the fifth section is comprised of the conclusion.

2- PDE and non-linear model for multi-effect desalination (MED) systems

In this paper, a particular type of multi-effect desalination systems, entitled AQUASOL has been examined. An overview of the system is shown the figure below [8].

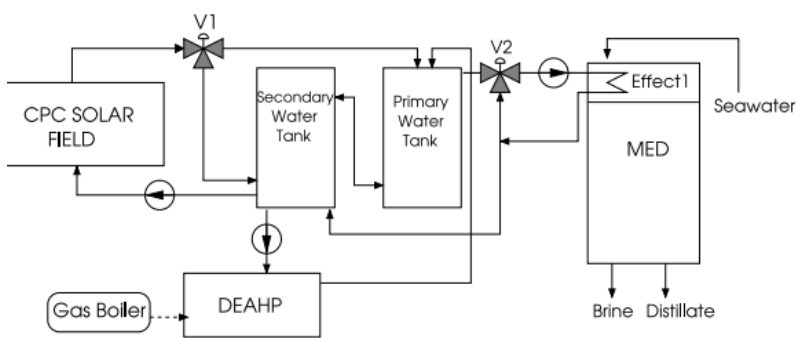

Figure 1: An overview of an AQUASOL process

According to Figure 1, multi-effect desalination systems are designed in such a way that hot high-pressure steam enters into the system from the boiler with a state close to saturation. Then, this steam suctions some part of the dead vapor remaining from the final stage while passage through the thermo compressor and its pressure drops to the incoming pressure of the first stage after the occurrence of the shock. With the spraying of water into the desuperheater, this steam changes into saturation vapor and enters the horizontal tubes (with bundle tube) of the first stage. The steam passing through the tubes gets distilled and becomes saturated while the film flow falling on tubes evaporates. The creation of vacuum in each stage is the requirement for evaporation at low temperatures which has been previously 
done by ejectors. The mathematical model describing the structure of Figure 1 is as follows:

$$
\begin{aligned}
& \rho . C_{p} \cdot A \cdot \frac{\partial T^{\prime}(t)}{\partial t} \\
& =\beta \cdot I(t)-\frac{H}{L_{e q}} \cdot\left(\bar{T}(t)-T_{a}(t)\right) \\
& -C_{p} \cdot \dot{m}_{e q}(t) \cdot \frac{T^{\prime}(t)-T_{i n}\left(t-d_{t i n}\right)}{L_{e q}} \\
& \bar{T}(t)=\frac{T^{\prime}(t)+T_{i n}\left(t-d_{t i n}\right)}{2}
\end{aligned}
$$

\begin{tabular}{|c|c|c|}
\hline unit & Symbol & parameter \\
\hline $\mathrm{kg} \mathrm{m}^{-3}$ & $\begin{array}{c}\text { The density of water } \\
\text { at a temperature of } \\
65^{\circ} \mathrm{C}\end{array}$ & $\rho$ \\
\hline$J k^{-1}{ }^{\circ} \mathrm{C}^{-1}$ & $\begin{array}{c}\text { Specific heat } \\
\text { capacity of water at } \\
\text { a temperature of } 65 \\
{ }^{\circ} \mathrm{C}\end{array}$ & $C_{p}$ \\
\hline$m^{2}$ & $\begin{array}{c}\text { Solar ray absorption } \\
\text { cross section }\end{array}$ & $A$ \\
\hline$m$ & $\begin{array}{l}\text { Parameter in the } \\
\text { model, exposure to } \\
\text { the sun }\end{array}$ & $\beta$ \\
\hline$J s^{-1} K^{-1}$ & Heat loss coefficient & $H$ \\
\hline$m$ & $\begin{array}{l}\text { The length of the } \\
\text { tubes in the } \\
\text { desalination }\end{array}$ & $L_{e q}$ \\
\hline $\mathrm{kg} / \mathrm{s}$ & $\begin{array}{l}\text { The current through } \\
\text { each of the tubes in } \\
\text { the desalination }\end{array}$ & $\dot{m}_{e q}$ \\
\hline${ }^{\circ} \mathrm{C}$ & $\begin{array}{c}\text { Temperature of } \\
\text { incoming water } \\
\text { desalination system }\end{array}$ & $T_{\text {in }}$ \\
\hline${ }^{\circ} \mathrm{C}$ & $\begin{array}{l}\text { The temperature of } \\
\text { the water trapped } \\
\text { inside the machine } \\
\text { desalination }\end{array}$ & $T_{a}$ \\
\hline$W m^{-2}$ & $\begin{array}{c}\text { The amount of solar } \\
\text { radiation }\end{array}$ & $I$ \\
\hline- & $\begin{array}{l}\text { Gaussian white } \\
\text { noise in the } \\
\text { desalination }\end{array}$ & $w$ \\
\hline
\end{tabular}

\section{Parameters of the model (1)}

\section{Presentation of the proposed control algorithm}

Nowadays, model predictive control (MPC) has been accepted as a standard control strategy to solve the control problems with constraints in industrial processes [9]. MPC controller makes use of the current states of the process as initial conditions at every sampling step and calculates the optimal control sequence by solving a problem of open-loop controller over a receding horizon [10].

)1( MPC controller is composed of a predictive model that is built based on the process model and a processor that performs optimization considering the constraints. The basic structure of MPC is shown in the following figure [11].

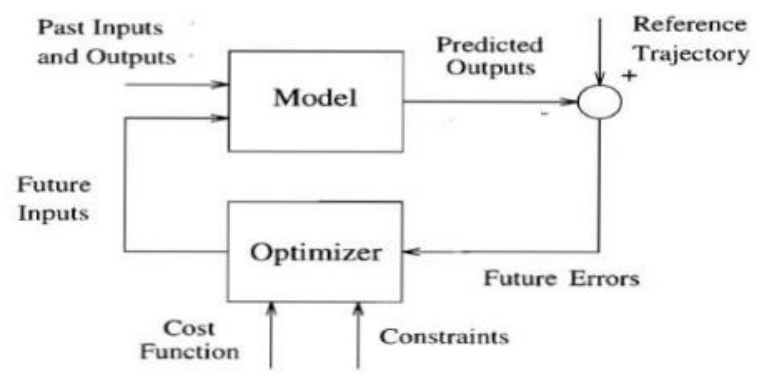

Figure 1: The basic structure of MPC

MPC strategy is predicted at each sampling step using the predictive model of the process and the process output over the predictive horizon of Np. Then, the sequence of control commands over the control horizon is achieved from the minimization of the cost function (that is formed from the sum of prediction error squares and control signal squares or its changes) with respect to the constraints. Afterwards, the first part of this sequence as the control signal is applied to the process at time $\mathrm{k}$ as per receding horizon control (RHC) and the rest of the sequence is ignored. These stages are repeated for the time $\mathrm{k}+1$ [11].

Model predictive controllers have been widely used in industrial processes for their proper control effect, but they suffer some shortcomings which have caused the results not be as expected. One of the shortcomings of them is that setting them is difficult and time-consuming when the available delays in the system are long; therefore, the results of 
the direct utilization of these controllers in the systems cannot be relied upon due to such delays in the model of MED systems. Another weakness of predictive controllers is related to the modelling of them, that is, the model used in them must be completely accurate. This is so while MED systems have uncertainty that in different parts and the ignorance of this uncertainty in the system is unavoidable. In this study, nonlinear predictive controller or NMPC has been suggested to overcome these shortcomings. The structure of NMPC is explained in the following.

Consider the following time invariant, discrete, and nonlinear Affine system:

$$
\begin{gathered}
x(k+1)=f(x(k))+g(x(k)) u(k) \\
+g_{d}(x(k)) d(k)
\end{gathered}
$$

$y(k)=C x(k)$

where $u(k) \epsilon U \subseteq R^{m}, x(k) \epsilon X \subseteq R^{n}, d(k)$, and $y(k)$ represent control input variable, reference, known disturbance, and output, respectively and $\mathrm{f}$ and $\mathrm{g}$ are nonlinear functions. The prediction of one step of reference variables over prediction horizon of $\mathrm{Np}$ can be obtained from the following relations:

$$
\begin{aligned}
& \hat{x}(k+1 \mid k)=f(x(k))+g(x(k)) u(k) \\
& \quad+g_{d}(x(k)) d(k)
\end{aligned}
$$

Since $\hat{x}(k+j-1 \mid k)$ includes the non-linear function of previous data, equation (2) might not provide analytical solutions for the prediction of more than one step. The above figure makes it impossible to achieve $\mathrm{u}(\mathrm{k}+1)$ and the future input elements in analytical formats. Accordingly, it is possible to consider the prediction of a step for $j \geq 2$ as follows by estimating the future of reference variables along with their reference trajectory:

$\hat{x}(k+j \mid k)$

$=f\left(w_{x}(k+j-1 \mid k)\right)$

$+g\left(w_{x}(k+j-1 \mid k)\right) u(k+j-1 \mid k)$ ) 4(

$+g_{d}\left(w_{x}(k+j-1 \mid k)\right) d(k+j-1 \mid k)$

where $w_{x}$ is the reference trajectory and its components are derived from the following equation:

$$
\begin{aligned}
w_{x}(k+j \mid k)= & \alpha w_{x}(k+j-1 \mid k) \\
& +(1-\alpha) x_{s p} ; j \\
& =1,2, \ldots, N_{p}-1
\end{aligned}
$$

where $\alpha \in[0,1) \quad$ is coefficient softening, $w_{x}(k \mid k)=x(k)$ and $x_{s p}$ are the desired values of reference variables. In this regard, the predictive model of the reference variables of Affine nonlinear process are expressed as follows:

$$
\begin{aligned}
\hat{x}(k+1 \mid k)=f & (x(k))+g(x(k)) u(k) \\
& +g_{d}(x(k)) d(k)
\end{aligned}
$$

$\hat{x}(k+j \mid k)$

$=f\left(w_{x}(k+j-1 \mid k)\right)$

)6(

$+g\left(w_{x}(k+j-1 \mid k)\right) u(k+j-1 \mid k)$

$+g_{d}\left(w_{x}(k+j-1 \mid k)\right) d(k+j-1 \mid k)$

$=2,3, \ldots, N_{p}$

\section{3- Simulation results}

In this section, the performance of the above3 mentioned controller on the nonlinear model of MED systems is evaluated and discussed. The simulations in this study have been performed based on the data in reference [12]. In this reference, one MED system has been put under examination for 16 days and the model of the system has been identified using the obtained data. In the following figures, the performance of the proposed controller in control of the system variables by means of MATLAB simulation software has been shown. 

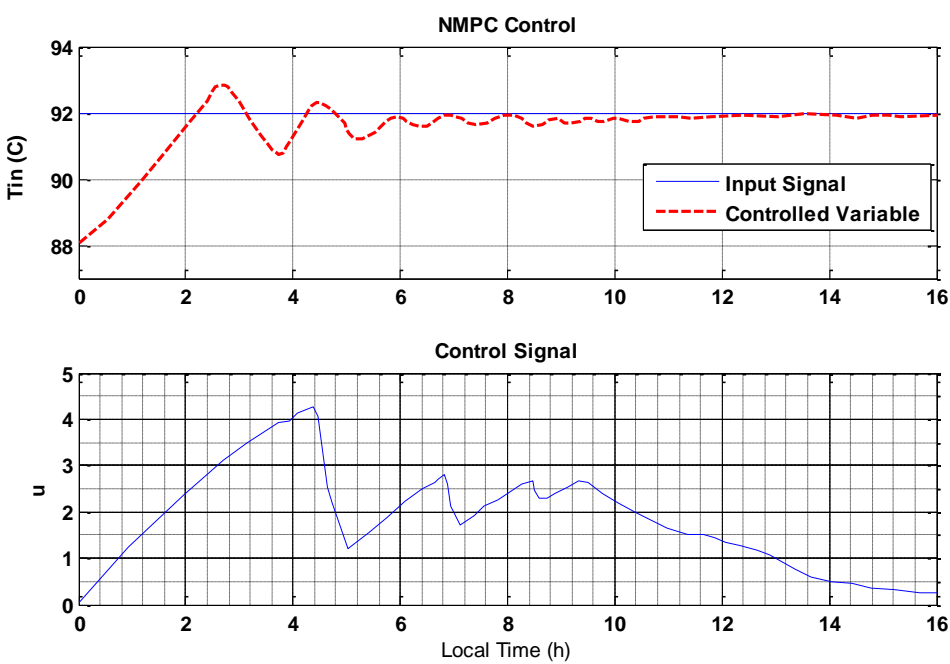

Figure 2: The above graph showing control of the water temperature entering the desalination system and the below graph showing the pertaining control signal
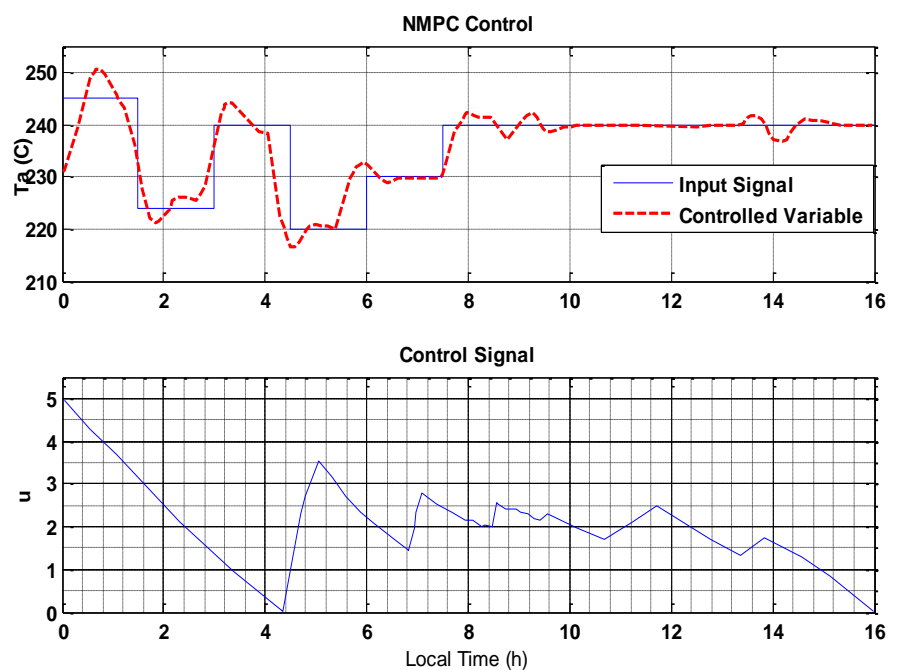

Figure 3: The above graph showing control of the water temperature trapped inside the desalination system and the below graph showing the pertaining control signal
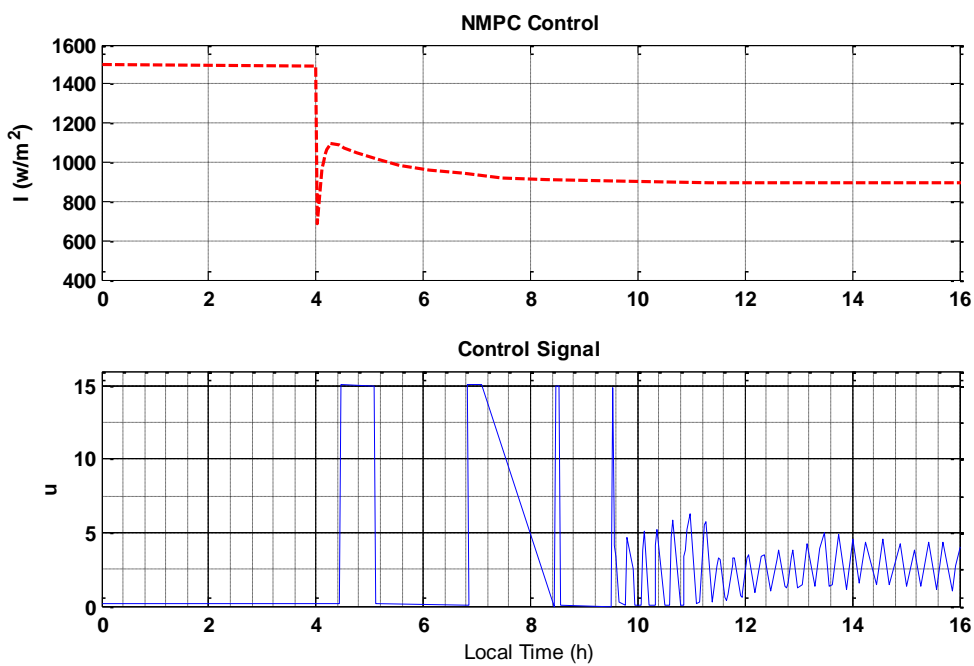

Figure 4: The above graph showing control of the amount of solar radiation into the desalination system and the below graph showing the pertaining control signal 


\section{Conclusion}

In this study, the main objective was to design an optimal controller for MED distillation systems. To this end, a PDE and nonlinear model out of these systems was proposed. The features available in this structure orient designers to predictive controllers. Since some features of normal MPC controllers such as their inability to cope with the delays in the system have led to the inefficiency of these controllers, nonlinear model predictive controller (NMPC) was implemented in this study. After the model selection and the implementation nonlinear predictive controller on it in MATLAB software, it was observed that the controller has been able to control the system variables as well as the maintenance of the system stability.

\section{References}

K. Sampathkumar, T. V. Arjunan, P. Pitchandi, and P. Senthilkumar, "Active solar distillation-a detailed review," Renew. Sustain. Energy Rev., vol. 14, no. 6, pp. 15031526, 2010.

V. Belessiotis and E. Delyannis, "Water shortage and renewable energies (RE) desalinationpossible technological applications," Desalination, vol. 139, no. 1, pp. 133-138, 2001.

T. V. Arjunan, H. Aybar, and N. Nedunchezhian, "Status of solar desalination in India," Renew. Sustain. Energy Rev., vol. 13, no. 9, pp. 24082418, 2009.

H. T. El-Dessouky and H. M. Ettouney, "Multipleeffect evaporation desalination systems. thermal analysis," Desalination, vol. 125, no. 1, pp. 259-276, 1999.

H. T. El-Dessouky, H. M. Ettouney, and F. Mandani, "Performance of parallel feed multiple effect evaporation system for seawater desalination," Appl. Therm. Eng., vol. 20, no. 17, pp. 1679-1706, 2000.

M. M. Ashour, "Steady state analysis of the Tripoli West LT-HT-MED plant," Desalination, vol. 152, no. 1, pp. 191-194, 2003.

A. B. Amer, "Development and optimization of ME-TVC desalination system," Desalination, vol. 249, no. 3, pp. 1315-1331, 2009.
A. J. Gallego and E. F. Camacho, "Adaptative state-space model predictive control of a parabolic-trough field," Control Eng. Pract., vol. 20, no. 9, pp. 904-911, 2012.

A. Gambier, T. Miksch, and E. Badreddin, “Faulttolerant control of a small reverse osmosis desalination plant with feed water bypass," in American Control Conference (ACC), 2010, 2010, pp. 3611-3616.

T. J. van den Boom and T. Backx, "Model predictive control," DISC Course Lect. Notes, vol. 16, 2010.

E. F. Camacho and C. B. Alba, Model predictive control. Springer Science \& Business Media, 2013.

L. Roca, M. Berenguel, L. Yebra, and D. C. Alarcón-Padilla, "Solar field control for desalination plants," Sol. Energy, vol. 82, no. 9, pp. 772-786, 2008. 